\title{
Термическая характеристика гранитов Бадьяюского массива (Приполярный Урал) по монациту
}

\author{
Денисова Ю.В. \\ Институт геологии Коми НЦ УрО РАН, Сыктывккар, yulden777@yandex.ru
}

\begin{abstract}
Аннотация. Монацит, являясь редкоземельным минералом, может рассматриваться не только как геохронометр, но, благодаря методике Дж. М. Монтеля (Montel, 1993), разработанной только для гранитов, и как геотермометр. Благодаря термометрии насыщения Дж. М. Монтеля автором были получены температуры кристаллизации минерала, а также температурный диапазон для заключительной стадии гранитогенеза пород Бадьяюского массива (Приполярный Урал). Полученные температуры находятся в диапазоне от $712^{\circ} \mathrm{C}$ до $755^{\circ} \mathrm{C}$ и в среднем составляют $730^{\circ} \mathrm{C}$. Эти данные были подтверждают температуры, рассчитанные по Дж.- Р. Пюпену (Рupin,1980) для циркона и по Е.Б. Ватсону (Harrison, Watson, 1984) для апатита.
\end{abstract}

Ключевые слова: геотермометр, монацит, гранит, Бадьяюский массив, Приполярный Урал.

\section{Thermal characteristics of granites of the Badyayu massif (the Subpolar Urals) according to monazite}

\author{
Denisova Yu.V. \\ Institute of geology of Komi SC UB RAS, Syktyvkar,yulden777@yandex.ru
}

\begin{abstract}
Monazite, being a rare-earth mineral, can be considered not only as a geochronometer, but, thanks to the method of J. M. Montel (Montel, 1993), developed only for granites, and as a geothermometer. Thanks to the saturation thermometry of J. M. Montel, the author obtained the crystallization temperatures of the mineral, as well as the temperature range for the final stage of granitogenesis of Badyayu massif rocks (the Subpolar Urals). The obtained temperatures range from $712^{\circ} \mathrm{C}$ to $755^{\circ} \mathrm{C}$ and average $730^{\circ} \mathrm{C}$. These data were confirmed by the temperatures calculated by J.-R. Pupin (Pupin, 1980) for zircon and by E. B. Watson (Harrison, Watson, 1984) for apatite.
\end{abstract}

Key words: geothermometer, monazite, granite, the Badyayu massif, the Subpolar Urals.

\section{Введение}

Несмотря на то, что монацит встречается во многих породах различного происхождения и возраста, его содержание обычно незначительно. Этот минерал переменного состава крайне интересен для изучения благодаря своей высокой термической стойкости. Монацит так же обычно характеризуется явно выраженной зональностью, состоящей из доменов совершенно разного состава и возраста. Такая возрастная зональность может быть использована для установки связи химического состава монацита с геологическими процессами (Williams and ets., 2007). Эти особенности позволяют использовать редкоземельный минерал для решения сложных вопросов генезиса и возраста различных пород. Принято считать, что монацит - мощный инструмент для изучения прежде всего истории метаморфических пород. Однако Дж. М. Монтелем была разработана методика определения температур по монациту для гранитов, что позволило использовать этот минерал и в качестве геотермометра.

Цель настоящего исследования - определение температурного режима формирования пород Бадьяюского массива на основе термометрии насыщения Дж. М. Монтеля.

\section{Объект исследований}

Расположенный в северо- восточной части Приполярного Урала Бадъяюский массив представляет собой пластинообразное гранитное тело (при длине 10 км и ширине 1 км), которое пересекает долины рр. Большая и Малая Бадьяю и далее прослеживается на юг до р. Селемью (рис. 1) (Махлаев, 1996).

По минеральному составу изученные граниты представляют собой лейкократовые (аляскитовые) породы, состоящие преимущественно из натрово-калиевого полевого шпата (50 \%); плаги- 


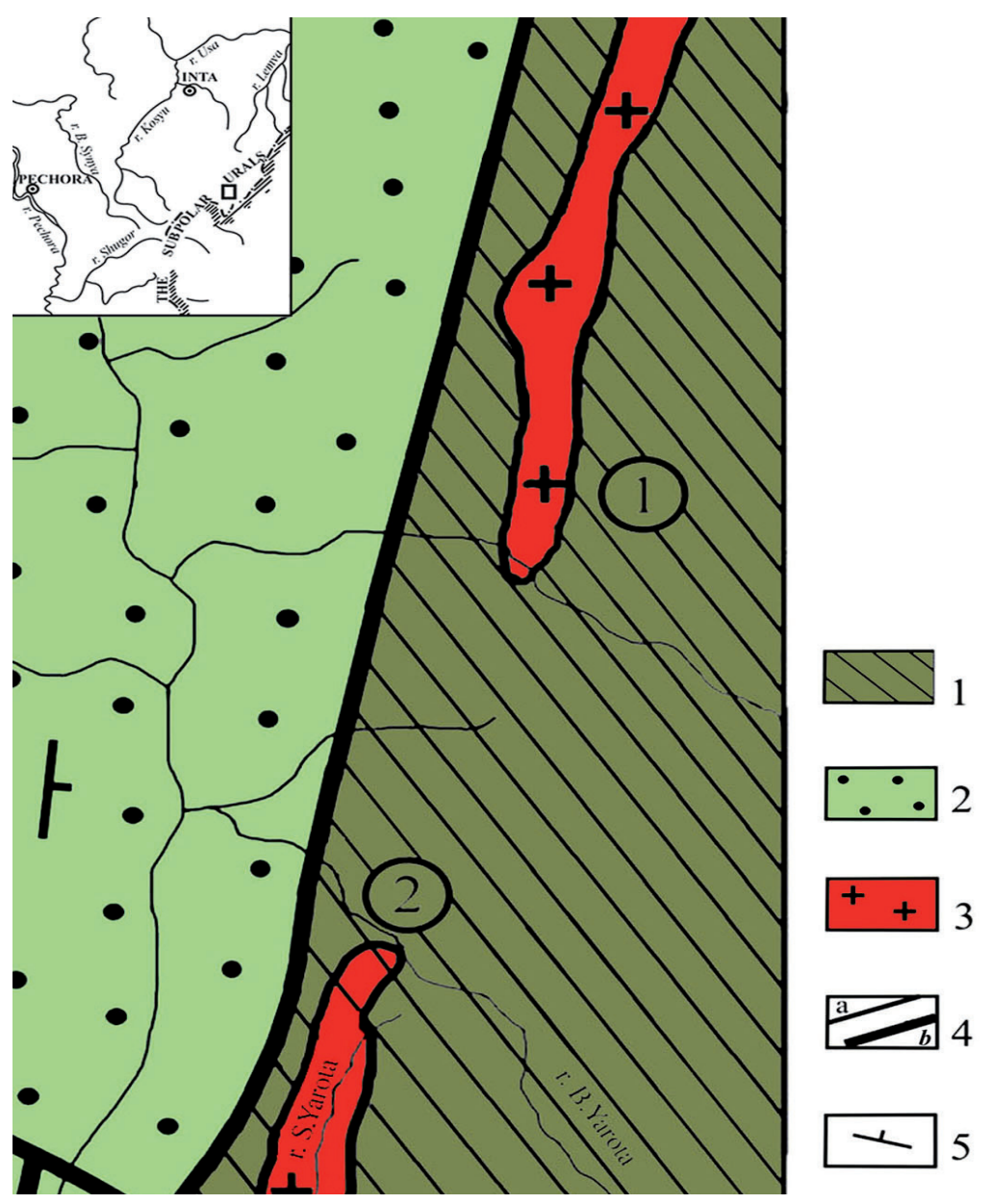

Рис. 1. а) Обзорная карта района.

б) Бадьяюский гранитный массив (по Пыстин, Пыстина, 2008).

1 - слюдяно-кварцевые сланцы, порфиры, порфириты, прослои мраморов и кварцитов; 2 - терригенно- карбонатные отложения; 3 - граниты; 4 - геологические границы: а - стратиграфические и магматические, б - тектонические; 5 - элементы залегания плоскостных структур. Массивы (цифры в кружочках): 1 - Бадьяюский; 2 - Яротский.

Fig. 1. a) Overview map of the area.

b) The Badyayu granite massif (according Pystin, Pystina, 2008).

1 - mica-quartz shales, porphyry, porphyry, layers of marbles and quartzites; 2 - terrigenous-carbonate deposits; 3 - granites; 4 - geological boundaries: a - stratigraphic and igneous, $\mathrm{b}$ - tectonic; 5 - elements of the occurrence of planar structures. Massifs (numerals in circles): 1 - the Badyayu massif; 2 - the Yarot massif.

оклаза (15 \%); кварца (25 \%). Так же всегда присутствуют биотит (3 \%), мусковит (7 \%). Для пород Бадьяюского массива повсеместно отмечается влияние катаклаза и последующая перекристаллизация. Малоизмененные граниты характеризуются преимущественно среднезернистой структурой и массивной текстурой (Фишман, Голдин, 1963, Фишман и др., 1969).

Акцессорные минералы представлены цирконом, апатитом, гранатом, титанитом, ортитом, флюоритом, пиритом и др. Монацит наблюдается крайне редко. Этот минерал встречается преимущественно в виде матовых округлых желтых зерен. Так же иногда отмечаются желто- розовые кристаллы призматического габитуса. Размер зерен составляет 0,15-0,20 мм, кристаллов - до 0. 30 мм. Монацит может быть включен в биотит или апатит. Так же обнаруживается по периферии зерен плагиоклаза (Фишман и др., 1969, Денисова, 2019).

\section{Методика исследования}

Монацит представляет собой минерал, относящийся к группе фосфатов лантаноидов. Повышенное содержание редкоземельных элементов преимущественно цериевой группы в этом минерале позволило Дж. М. Монтелю (Montel, 1993) разработать методику определения температуры насыщения по монациту для гранитов по их химическому составу.

Расчетная формула Дж. М. Монтеля устанавливает связь между температурой кристаллизации монацита и монацитсодержащей породой и содержанием легких редких элементов, породообразующих элементов и количеством воды в изучаемом граните:

$$
\ln (\text { LREE })=9.5+2.34 * \mathrm{M}_{\mathrm{mz}}+0.3879 * \sqrt{\mathrm{H}_{2} \mathrm{O}}-\frac{13318}{\mathrm{~T}^{\mathrm{K}}}
$$




$$
\begin{gathered}
\text { где LREE }=\frac{\sum \frac{\mathrm{REE}_{\mathrm{i}}}{\mathrm{REE}}}{\mathrm{X}_{\mathrm{mz}}} ; \\
\mathrm{M}_{\mathrm{mz}}=100 * \frac{\mathrm{Na}+\mathrm{K}+\mathrm{Li}+2 \mathrm{Ca}}{\mathrm{Al} *(\mathrm{Al}+\mathrm{Si})} .
\end{gathered}
$$

Соответственно температура насыщения по монациту для гранита:

$$
\mathrm{T}^{\mathrm{c}}=\frac{13318}{9.5+2.34 * \mathrm{M}_{\mathrm{mz}}+0.3879 * \sqrt{\mathrm{H}_{2} \mathrm{O}}-\ln (\mathrm{LREE})}-273.15
$$

где $\mathrm{REE}_{\mathrm{i}}$ - содержание La, Ce, $\mathrm{Pr}, \mathrm{Nd}, \mathrm{Sm}, \mathrm{Gd}$ в расплаве, атом. вес, REE - суммарное содержание LREE в расплаве, атом. вес,

$\mathrm{X}_{\mathrm{mz}}$ - суммарное содержание LREE в расплаве, мол. вес,

$\mathrm{M}_{\mathrm{mz}}$ - соотношение катионов,

$\mathrm{H}_{2} \mathrm{O}$ - предполагаемое содержание воды в расплаве,

$\mathrm{T}^{\mathrm{K}}$ - температура, Кельвин,

$\mathrm{T}^{\mathrm{C}}$ - температура, Цельсий.

\section{Термометрия насыщения монацита для гранитов Бадъяюского массива}

Температура насыщения по монациту для рассматриваемых пород определена на основе данных силикатного метода, полученных в ЦКП «Наука» Институте геологии Коми НЦ УрО РАН (Сыктывкар, аналитик О. В. Кокшарова), а так же данных ICP- MS метода, определенных в Институте геологии и геохимии (Екатеринбург, аналитик Ю. Л. Ронкин) (табл. 1).

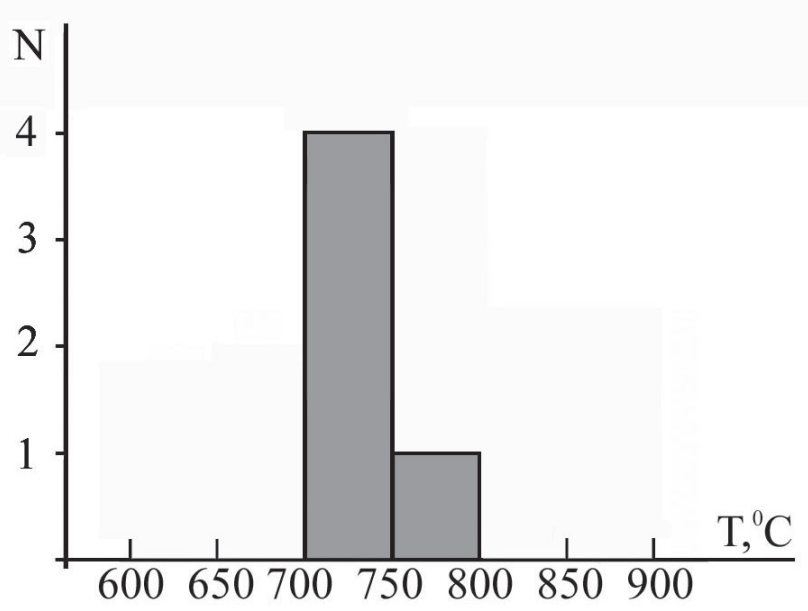

Рис. 2. Гистограмма распределения температур насыщения по монациту для гранитов Бадьяюского массива.

Fig. 2. Histogram of the monazite saturation temperature distribution for the granites of the Badyayu massif.

Согласно гистограмме, построенной на основе рассчитанных показателях термометрии насыщения, во время кристаллизации монацита температура магматического расплава колебалась в достаточно узком пределе - от 700 до $750^{\circ} \mathrm{C}$ (рис. 2) и в среднем составляла $730^{\circ} \mathrm{C}$. М. В. Фишман и его коллеги (Фишман и др., 1968) в своих ранних исследованиях при выявлении последовательности выделения минералов при формировании гранитов Приполярного Урала установили, что монацит сформировался в период поздней стадии магматического этапа. Это свидетельствует о том, что заключительная фаза становления пород Бадьяюского массива проходила при достаточно высоких температурах

\section{Заключение}

Анализ химического состава гранитов Бадьяюского массива с применением методики Дж. М. Монтеля подтверждает ранее полученные выводы автора, основанные на данных по эволюционно- кристалломорфологическому анализу по циркону (от 773 до $912^{\circ} \mathrm{C}$ ) и термометрии насыщения по апатиту (от $634^{\circ} \mathrm{C}$ до $863^{\circ} \mathrm{C}$ ) для этого массива, что изученные породы являются высокотемпературными образованиями (Денисова, 2016, 2020). Кроме того, по монациту, период кристаллизации которого приходится на завершающую стадию гранитогенеза, удалось установить, что станов- 
ления пород Бадьяюского массива на заключительной фазе магматического процесса происходили при достаточно узком высокотемпературном диапазоне - от $712^{\circ} \mathrm{C}$ до $755^{\circ} \mathrm{C}$.

Таблица 1. Химический состав гранитов Бадьяюского массива.

Table 1. Chemical composition of the Badyayu massif granites.

\begin{tabular}{|c|c|c|c|c|c|}
\hline Номер пробы & Б-2 & Б-3 & Б-5 & Б-7 & Б-8 \\
\hline \multicolumn{6}{|c|}{ Основной компонент, мас. \% } \\
\hline $\mathrm{SiO}_{2}$ & 74.92 & 75.42 & 76.82 & 74.42 & 75.89 \\
\hline $\mathrm{TiO}_{2}$ & 0.35 & 0.33 & 0.22 & 0.18 & 0.21 \\
\hline $\mathrm{Al}_{2} \mathrm{O}_{3}$ & 11.27 & 11.72 & 11.05 & 12.48 & 11.78 \\
\hline $\mathrm{FeO}$ & 1.90 & 0.95 & 1.82 & 0.67 & 1.01 \\
\hline $\mathrm{Fe}_{2} \mathrm{O}_{3}$ & 1.32 & 0.89 & 0.55 & 1.01 & 1.12 \\
\hline $\mathrm{MnO}$ & 0.02 & 0.02 & 0.01 & 0.03 & 0.04 \\
\hline $\mathrm{MgO}$ & 0.28 & 0.31 & 0.28 & 0.26 & 0.22 \\
\hline $\mathrm{CaO}$ & 1.04 & 1.02 & 0.59 & 1.02 & 0.31 \\
\hline $\mathrm{Na}_{2} \mathrm{O}$ & 2.54 & 3.37 & 2.96 & 3.33 & 2.94 \\
\hline $\mathrm{K}_{2} \mathrm{O}$ & 5.26 & 4.57 & 4.12 & 5.02 & 4.89 \\
\hline $\mathrm{P}_{2} \mathrm{O}_{5}$ & 0.03 & 0.03 & 0.05 & 0.01 & 0.01 \\
\hline ппп & 0.82 & 0.82 & 1.20 & 1.21 & 1.29 \\
\hline$\sum$ & 99.76 & 99.45 & 99.67 & 99.64 & 99.71 \\
\hline $\mathrm{H}_{2} \mathrm{O}^{-}$ & 0.11 & 0.10 & 0.11 & 0.17 & 0.11 \\
\hline \multicolumn{6}{|c|}{ Редкие элементы, г/т } \\
\hline $\mathrm{La}$ & 14.46 & 15.3 & 24.2 & 14.42 & 11.81 \\
\hline $\mathrm{Ce}$ & 32.32 & 33.1 & 43.3 & 29.23 & 25.15 \\
\hline $\operatorname{Pr}$ & 3.98 & 4.01 & 5.02 & 3.42 & 2.89 \\
\hline $\mathrm{Nd}$ & 15.91 & 15.9 & 17.6 & 13.26 & 11.33 \\
\hline $\mathrm{Sm}$ & 3.64 & 3.33 & 3.79 & 2.92 & 2.48 \\
\hline $\mathrm{Eu}$ & 0.66 & 0.8 & 0.59 & 0.52 & 0.45 \\
\hline $\mathrm{Gd}$ & 3.49 & 3.33 & 3.77 & 2.88 & 2.45 \\
\hline $\mathrm{Tb}$ & 0.55 & 0.65 & 0.78 & 0.49 & 0.41 \\
\hline Dy & 3.16 & 3.53 & 3.92 & 2.88 & 2.27 \\
\hline Ho & 0.56 & 0.72 & 0.83 & 0.48 & 0.41 \\
\hline Er & 1.51 & 2.13 & 2.36 & 1.32 & 1.09 \\
\hline $\mathrm{Tm}$ & 0.21 & 0.32 & 0.38 & 0.21 & 0.17 \\
\hline $\mathrm{Yb}$ & 1.33 & 1.99 & 2.12 & 1.13 & 0.89 \\
\hline $\mathrm{Lu}$ & 0.22 & 0.31 & 0.38 & 0.2 & 0.17 \\
\hline \multicolumn{6}{|c|}{ Температура, ${ }^{\circ} \mathrm{C}$} \\
\hline $\mathrm{T}^{\mathrm{C}}$ & 755 & 712 & 734 & 726 & 719 \\
\hline
\end{tabular}

\section{Литература}

1. Денисова Ю.В. Термометрия циркона из гранитоидов Приполярного Урала// Вестник Института геологии Коми НЦ УрО РАН. Сыктывкар. № 12. 2016. С. 37-44.

2. Денисова Ю.В. Термометрия насыщения циркона, апатита, монацита (Кожимский массив, Приполярный Урал) // Известия Коми научного центра УрО РАН. № 3 (39). Сыктывкар. 2019. С. 25-30. doi 10.19110/1994-5655-2019-3-47-52.

3. Денисова Ю.В. Типоморфические и типохимические особенности акцессорного апатита из гранитов Бадьяюского массива (Приполярный Урал) // Труды Ферсмановской научной сессии ГИ КНЦ РАН. № 17. Апатиты. 2020. С. 168-171. doi: https://doi.org/10.31241/FNS.2020.17.031.

4. Махлаев Л.В. Гранитоиды севера Центрально- Уральского поднятия (Полярный и Приполярный Урал). Екатеринбург. Изд-во: УрО РАН. 1996. 189 с. 
5. Пыстин А.М., Пыстина Ю.И. Метаморфизм и гранитообразование в протерозойско- раннепалеозойской истории формирования Приполярноуральского сегмента земной коры // Литосфера. 2008. № 11. C. 25-38.

6. Фишман М.В., Голдин Б.А. Гранитоиды центральной части Приполярного Урала. М.- Л. Изд-во: АН СССР. 1963. $105 \mathrm{c}$.

7. Фишман М.В., Юшкин Н.П., Голдин Б.А., Калинин Е.П. Основные черты магматизма и метаморфизма в центральной части Приполярного и Полярного Урала // Геохимия, минералогия и петрография севера Урала и Тимана. Сыктывкар. 1969. С. 7-25.

8. Фишман М.В., Юшкин Н.П., Голдин Б.А., Калинин Е.П. Минералогия, типоморфизм и генезис акцессорных минералов изверженных пород севера Урала и Тимана. М.- Л. Изд-во: Наука. 1968. 252 с.

9. Harrison T.M., and Watson E.B. The behavior of apatite during crustal anatexis: Equilibrium and kinetic considerations // Geochim. Cosmochim. Acta. 1984. V. 48. P. 1467-1477.

10. Montel J. M. A model for monazite/melt equilibrium and application to the generation of granitic magmas // Chem. Geol. V. 110. 1993. P. 127-146.

11. Pupin J.- P. Zircon and granite petrology // Contrib. Miner. Petrol. 1980. V. 73. P. 207-220.

12. Williams M.L., Jercinovich M.J. and Hetherington K.J. Monazite microprobe geochronology: understanding geological processes by integrating composition and chronology // Annual Review of Earth and Planetary Sciences. 2007. V. 35 (1). P. 137. 